\title{
Epidemiological and phylogenetic analyses of COVID-19 in Africa using open-source sequence data.
}

\author{
Chigozie NWACHUKWU ${ }^{1}$, C Raina MacIntyre ${ }^{1}$, and Haley Stone ${ }^{1}$ \\ ${ }^{1}$ University of New South Wales
}

January 25, 2021

\begin{abstract}
Between late December 2019 to early September 2020, over 10 million people globally were reportedly infected by the severe acute respiratory syndrome coronavirus-2 (SARS-CoV-2), responsible for the coronavirus disease-2019 (COVID-19). In Africa, more than 300,000 infection occurred within the period, from which several viral genetic sequences were generated. Phylogenetic reconstruction of genomic data can provide epidemiological inferences about time of pathogen introduction, epidemic growth rate and temporal-spatial spread of the infection during disease outbreak. In this work, we studied the genetic epidemiology of COVID-19 in Africa. Genetic sequence data of SARS-CoV-2 and metadata from African countries were obtained from open-source sequence database hosted by the GISAID initiative. Whole genome sequences were subjected to multiple sequence alignment, from which Maximum Likelihood phylogenetic tree was constructed based on the general time reversible model. Of the 227 genetic sequences obtained for 9 African countries (DRC=133, Senegal=23, South Africa=20, Ghana=15, Tunisia=6, Algeria=3, Gambia=3, Egypt=2 and Nigeria=2), 220 were whole genome sequences while 7 were partial genome sequences of the surface glycoprotein S. Phylogenetic analysis confirmed multiple introductions of the virus to the continent from multiple external sources prior to local adaptation and spread. The very close alignment of three viruses - Ghana/1659_S14/2020|EPI_ISL_422405, DRC/KN0054/2020|EPI_ISL_417437, and South_Africa/R05475/2020|EPI_ISL_435059 - to the reference Wuhan strain on the time tree, suggests possible introduction and circulation of the virus into the continent much earlier than when the first case was announced on February 15 2020. In conclusion, this study provided evidence to support multiple introductions of SARS-CoV-2 into Africa, and further suggests that the virus may have already been circulating in the continent prior to official reporting of the first case. Also, there is strong impression to infer likely genetic adaptation of the virus in the continent that may account for the close clustering of isolates from different countries.
\end{abstract}

\section{Hosted file}

Publication draft TEID.pdf available at https://authorea.com/users/391693/articles/505722epidemiological-and-phylogenetic-analyses-of-covid-19-in-africa-using-open-sourcesequence-data

\section{Hosted file}

Table 1.pdf available at https://authorea.com/users/391693/articles/505722-epidemiologicaland-phylogenetic-analyses-of-covid-19-in-africa-using-open-source-sequence-data 


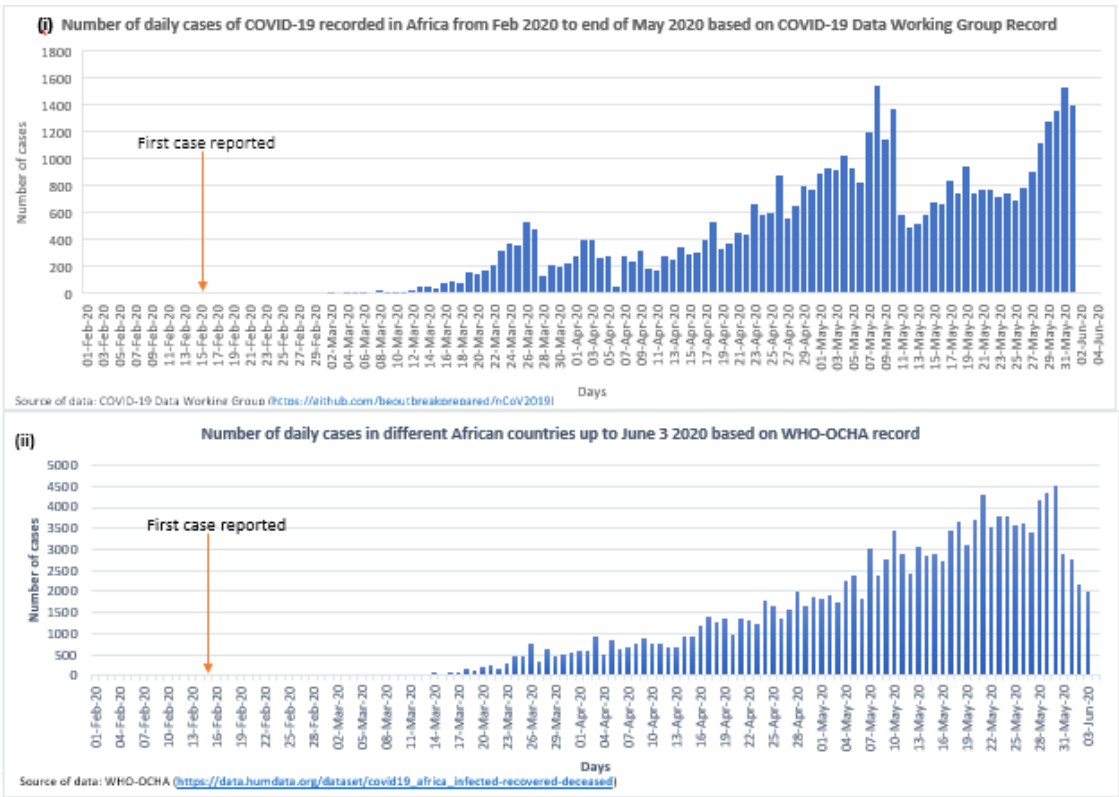

\section{Hosted file}

Table 2.pdf available at https://authorea.com/users/391693/articles/505722-epidemiologicaland-phylogenetic-analyses-of-covid-19-in-africa-using-open-source-sequence-data

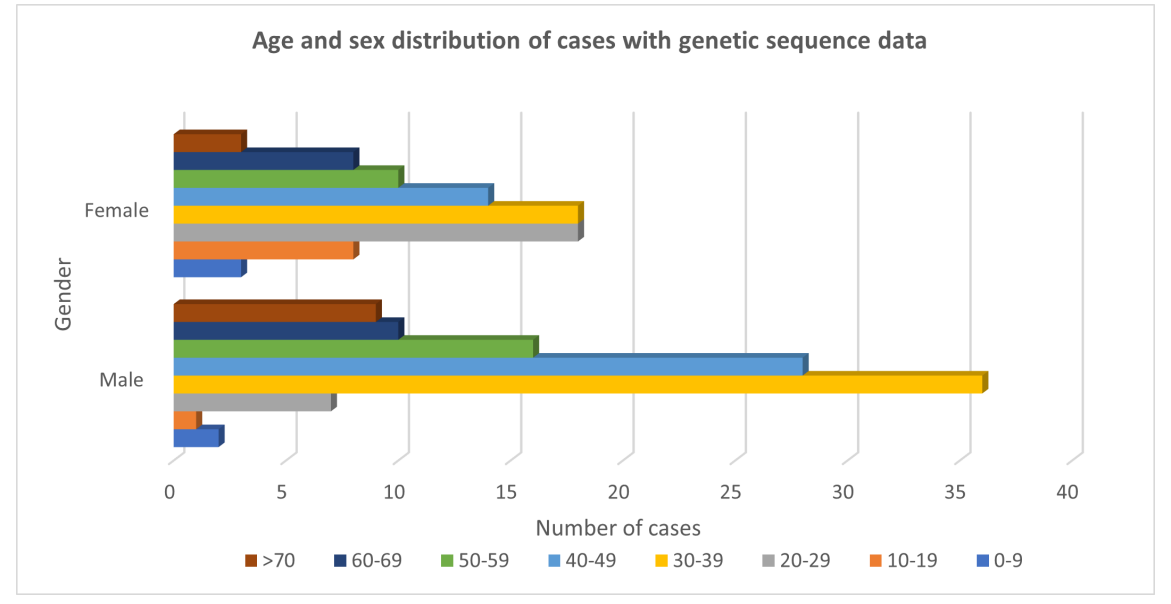




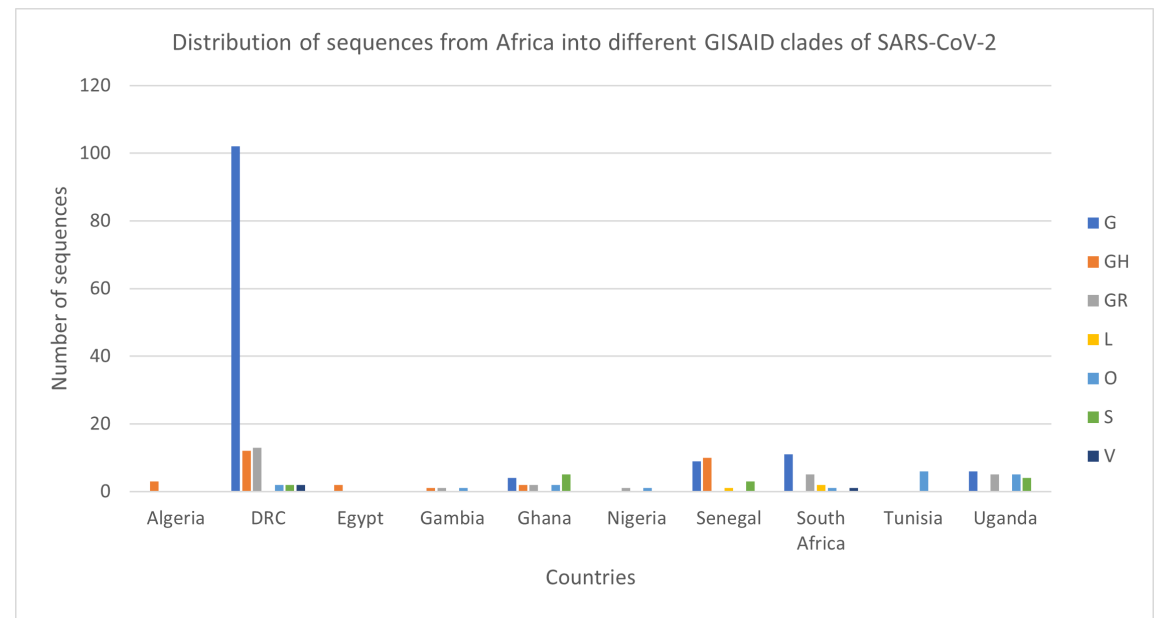




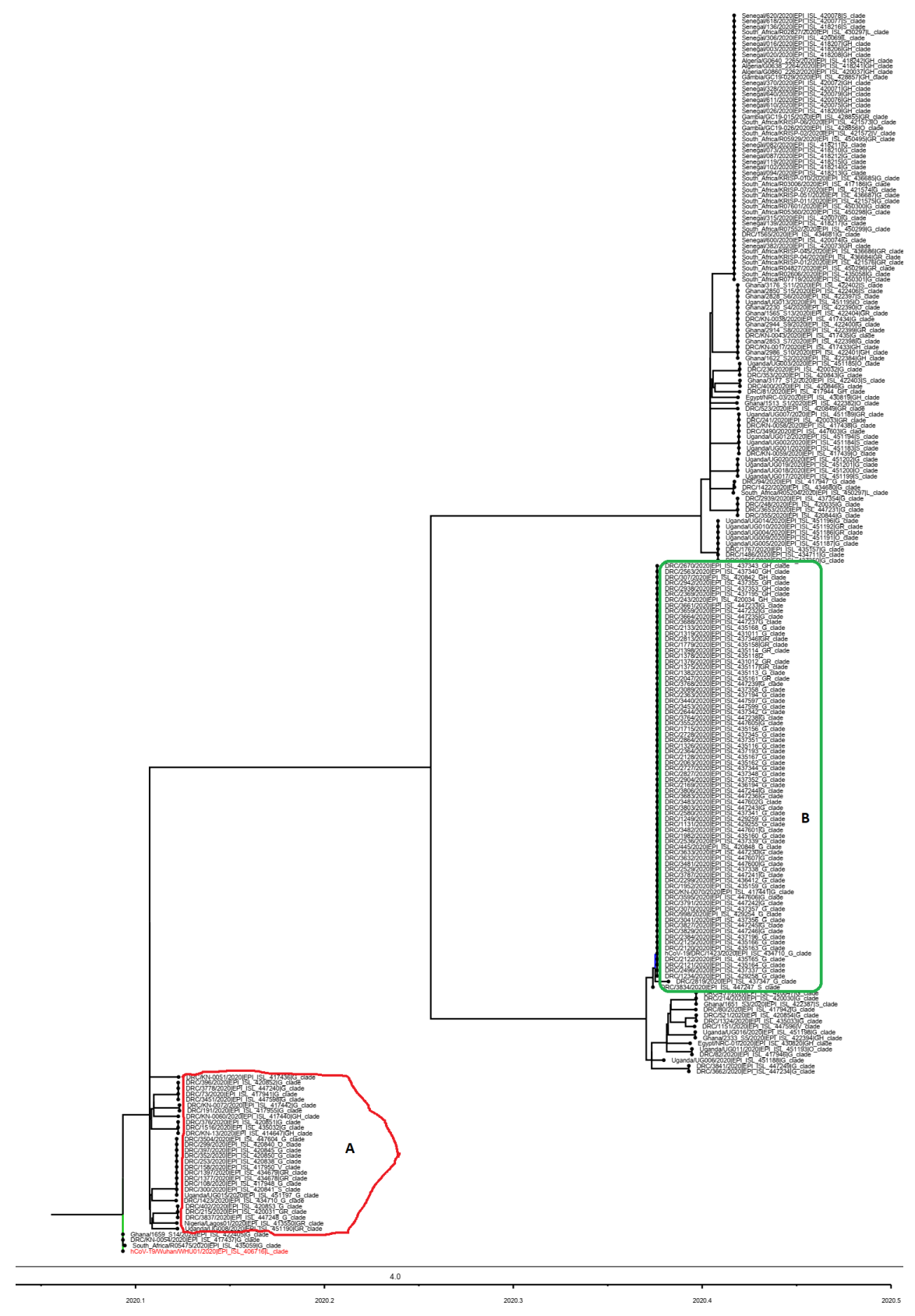

